\title{
A preliminary study: MUC5B promoter polymorphism and its association with IPF
}

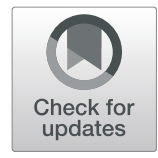

Hoda Ali Abu Yusuf', Mohamed Galal', Safy Kaddah¹, Marwa el Sharkawy², Mohamed Shaaban Mousa' and Heba Moussa ${ }^{1 *}$

\begin{abstract}
Background: The (T) allele of MUC5B gene is strongly correlated with idiopathic pulmonary fibrosis (IPF) and interstitial lung diseases (ILD) related to autoimmune conditions in Caucasians, but no data is available regarding this polymorphism in the Egyptian patients.

Results: This study is an observational cross-sectional study; the percentage of the (T) allele of MUC5B gene promoter in normal Egyptian persons in this study was $20 \%$. This polymorphism is strongly related with risk for development of UIP/IPF in Egyptian patients compared to the other 2 groups ( $P$ value $<0.001$ ). The MUC5B polymorphism has no role for developing interstitial lung disease in autoimmune diseases.

Conclusions: This study showed the potential role of MUC5B promoter polymorphism in IPF patients. Further multicentric studies are essential to be conducted deploying larger cohorts and different ethnic populations for further evaluation of these polymorphisms correlation.
\end{abstract}

Keywords: MUC5B, Gene polymorphisms, IPF

\section{Background}

Idiopathic pulmonary fibrosis (IPF) is defined as a chronic progressive type of idiopathic interstitial pneumonias (IIPs) of unknown cause, occurring mainly in elderly, limited to the lungs, and associated with the histopathologic and/or radiologic pattern of usual interstitial pneumonia (UIP) [1]. It is the worst form of idiopathic interstitial pneumonias (IIPs) with a bad prognosis $[2,3]$.

The incidence of IPF increases with old age with peaks in the 6th decade of age, and it is more common in males than females [4]. Approximately, the median survival is 3 years from time of diagnosis [5]. However, multiple studies on IPF show substantial differences as regards demographic distribution in different world region [6]. Worldwide, the mean prevalence of IPF ranges from 6 to 32 per 100,000 [7].

\footnotetext{
* Correspondence: habhoubas2002@yahoo.com

${ }^{1}$ Chest Department, Cairo University, Giza, Egypt

Full list of author information is available at the end of the article
}

Several studies illustrated the potential risk of cigarette smoking and other environmental exposures to the progression of IPF $[1,8,9]$. The risk for IPF is mostly determined by polygenetic variants [10]. It is supposed that IPF results from the altered behavior of injured alveolar epithelial cells, which produce growth factors that induce growth of resident fibroblasts and thus fibrocyte accumulation and epithelial to mesenchymal transition with development of IPF pathology [11].

Therefore, many investigations have been carried out to determine the genetic predisposition for IPF focusing on cytokines, growth factors, and the human leukocyte antigen (HLA) group polymorphisms [12-14].

Many studies confirmed the presence of strong correlation of the MUC5B polymorphisms with IPF in both European Caucasian populations and two wide genomic studies [15-19].The common variant rs35705950 is found in the promoter region of the mucin $5 \mathrm{~B}$ (MUC5B) gene encoding the mucin 5 subtype B. It is both a gelforming mucin and a major component of mucus in the respiratory tract $[20,21]$. Seibold et al. [22] were the first

\section{Springer Open}

(๑) The Author(s). 2020 Open Access This article is licensed under a Creative Commons Attribution 4.0 International License, which permits use, sharing, adaptation, distribution and reproduction in any medium or format, as long as you give appropriate credit to the original author(s) and the source, provide a link to the Creative Commons licence, and indicate if changes were made. The images or other third party material in this article are included in the article's Creative Commons licence, unless indicated otherwise in a credit line to the material. If material is not included in the article's Creative Commons licence and your intended use is not permitted by statutory regulation or exceeds the permitted use, you will need to obtain permission directly from the copyright holder. To view a copy of this licence, visit http://creativecommons.org/licenses/by/4.0/. 
to use linkage and fine mapping to identify the $\mathrm{p}$ terminus of chromosome 11. Interestingly, any pattern of $\mathrm{T}$ allele either heterozygous or homozygous is at higher risk for IPF.

Up to date there is a limited data about the strong correlation between MUC5B variant and IPF among the Middle East population. Therefore our study aimed to detect the presence of the common variant of MUC5B and its association with IPF.

\section{Methods}

\section{Study design}

This study was carried out at a pulmonary medicine department in collaboration with the Clinical Pathology department at Faculty of medicine, Cairo University (Kasr Alainy hospital) of 18 months duration started from November 2015.

This study is an observational cross-sectional study. It consisted of 3 groups: group I, 42 UIP/IPF patients; group II, 47 other ILD patients; and group III, control group of 40 healthy persons.

All IPF patients were diagnosed according to the official 2013 ATS/ERS consensus criteria [3]. Highresolution chest tomography (HRCT) showed typical manifestations of IPF in all patients [1, 3]. ILD patients other than UIP/IPF were diagnosed based on clinical and radiological features, while diagnosis by VATS (video-assisted thoracic surgery) was done for the cases with atypical radiological image, (five patients were subjected to VATS and were diagnosed to have NSIP). The latter group (group II) included interstitial lung diseases related to autoimmune conditions and they were 13 cases whose HRCT showed UIP pattern and 34 cases whose HRCT showed NSIP pattern.

All patients have the following data: age, sex, past medical and smoking history, raising birds, occupational and environmental exposure, physical findings, laboratory data, and high resolution computed tomography (HRCT) scans.

Patients who suffered from systemic illness with pulmonary affection (i.e., heart failure, renal failure), pulmonary infections, and malignancy (either primary or metastatic to lung) were excluded from the study.

The study was finally accepted by the Committee of ethics at the Faculty of Medicine, Cairo University, and consents were obtained from all enrolled persons in this study.

\section{Specimen collection and DNA extraction}

DNA extraction was performed from $3 \mathrm{ml}$ of peripheral blood on EDTA for all persons using a GF-1 blood DNA extraction kit (Vivantis Technologies, Malaysia).

\section{PCR amplification of the primers}

Primers to amplify 976 basepair (bp) in the promotor area of MUC5B gene (rs35705950) according to the protocol [23]. PCR was performed using hotstar PCR mastermix (GeneDirex, Taiwan).

\section{Detection of the MUC5B gene by RFLP method}

Ten microliters of the reaction was digested in a mixture that contained $0.5 \mu \mathrm{l}$ of the restriction enzyme HaeII (Vivantis Technologies, Malaysia), $2 \mu \mathrm{l}$ of 10X digestion buffer, and $7.5 \mu \mathrm{l}$ of PCR product for a volume total of $10 \mathrm{ml}$. The test was executed for $16 \mathrm{~h}$ at $37^{\circ} \mathrm{C}$. The product was separated on a $1.5 \%$ agarose gel containing ethidium bromide ( $30 \mathrm{~min}$ at $120 \mathrm{~V}$ ) by electrophoresis. The genotypes observed under UV illumination were detected as follows: GG genotype showed two bands of $616 \mathrm{bp}$ and $360 \mathrm{bp}$, the GT genotype showed three bands (976, 616, 360), and the TT genotype showed one band (360 bp) as shown in Fig. 1.

\section{Statistical analysis}

Pre-coded data was analyzed through the Statistical Package of Social Science Software program, version 23 (IBM SPSS Statistics for Windows, Version 23.0. Armonk, NY: IBM Corp.). Data was summarized as mean, standard deviation (SD), median, and range for quantitative variables, and frequency and percentage for qualitative ones. Comparison between groups was performed using independent sample $t$ test (if parametric data) or Mann Whitney test (if non-parametric data) for quantitative variables and Chi square and Fisher's exact test for qualitative ones. $P$ values less than or equal to 0.05 were considered of statistical significance.

\section{Results}

The demographic data of the 3 groups are summarized in Table 1.

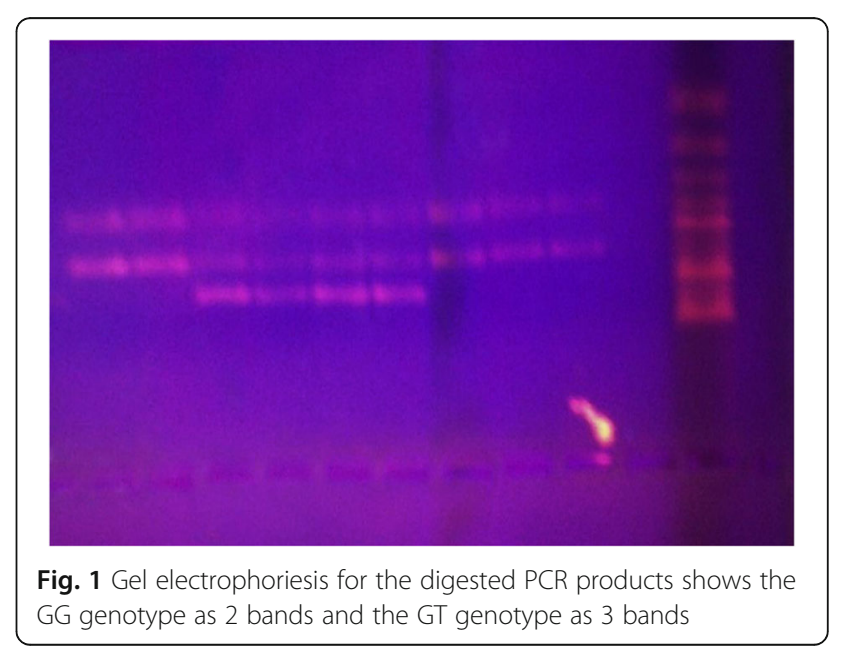


Table 1 Demographic characteristics of the three groups

\begin{tabular}{|c|c|c|c|}
\hline & IPF patients (group I) $(n=42)$ & Other ILD patients (group II) $(n=47)$ & Control subjects (group III) $(n=40)$ \\
\hline \multicolumn{4}{|l|}{ Age, years } \\
\hline Range & $32-58$ & $20-74$ & $25-63$ \\
\hline Mean \pm SD & $47.8 \pm 8.8$ & $43.7 \pm 11.1$ & $43.2 \pm 13.4$ \\
\hline \multicolumn{4}{|l|}{ Sex } \\
\hline Male & 17 (40.5\%) & $10(21.3 \%)$ & $10(25 \%)$ \\
\hline Female & 25 (59.5\%) & $37(78.7 \%)$ & $30(75 \%)$ \\
\hline \multicolumn{4}{|l|}{ Smoking status } \\
\hline Smokers & 15 (35.7\%) & $5(10.6 \%)$ & $8(20 \%)$ \\
\hline Non-smokers & $27(64.3 \%)$ & $42(89.4 \%)$ & $32(80 \%)$ \\
\hline \multicolumn{4}{|c|}{ History of raising birds } \\
\hline Yes & $14(33.3 \%)$ & $17(36.2 \%)$ & \\
\hline No & $28(66.7 \%)$ & $30(63.8 \%)$ & \\
\hline
\end{tabular}

Data demonstrated that the allele frequency of the genotypes of MUC5B promoter polymorphism were as follows: 21 GT (50\%), 16 GG (38.1\%), 5 TT (11.9\%) among the IPF patients (group I), and 15 GT (31.9\%), 30 GG (63.8\%), and 2 TT (4.3\%) among other ILD patients (group II). The frequency for the minor allele (T) of the polymorphism was $20 \%$ in the control group (group III) (Table 2). The frequency of the minor allele $(\mathrm{T})$ of the polymorphism was significantly higher among the IPF patients in relation to the other two studied groups ( $P$ value $<0.001$ ) (Table 2).

Although there was female gender predominance among our patients and all were housewives, there were 25 IPF female patients (59.5\%) (group I) and 37 other ILD patients (78.7\%) (group II). However, there was no statistical difference among group I and group II as regards the gender. Also, there was no statistical difference in the mean of age among the 3 studied groups.

In the healthy group (group III), there was no statistical significance in the $T$ allele between males and females. In IPF patients (group I) and other ILD patients (group II), there was also no significance in the $\mathrm{T}$ allele detected between males and females (Table 3).

There were 15 smokers among the IPF patients (group I) compared to 5 smokers among the other ILD patients (group II) with significant difference between the 2 groups $P$ value 0.0006 . In the IPF patients (group 1 ), we detected that the presence of the allele $(\mathrm{T})$ in smokers was higher in 13 patients, $P$ value $=0.014$. In the other 2 groups, the distribution of the $(\mathrm{T})$ allele in smokers was present in 2 cases with no statistical significance in the $\mathrm{T}$ allele as regards the smoking status of the subjects (Table 4).

Our results showed there were 14 subjects raising birds among group I compared to 17 subjects raising birds among group II with no statistical difference between the 2 groups $(P$ value $=0.779)$. In the IPF patients raising birds (group I), the study demonstrated that the presence of the (T) allele in 4 patients, $P$ value $=0.002$. In the other ILD patient raising birds (group II), the distribution of the minor-allele $(\mathrm{T})$ was present in 6 cases with no significant difference (Table 5).

\section{Discussion}

In Egypt, a little attention has been paid to define the possible genetic liability for IPF. In this study, we searched for the correlation between the (T) allele of the mucin gene subtype B and the risk for ILD. The minor allele $(\mathrm{T})$ was detected in 6 individuals as heterozygous genotype (GT) and in only 2 individuals as homozygous

Table 2 The allele frequency of the genotypes of MUC5B promoter polymorphism among the 3 studied groups

\begin{tabular}{|c|c|c|c|c|c|}
\hline & IPF patients (group I) $(\boldsymbol{n}=42)$ & Other ILD patients (group II) $(\boldsymbol{n}=47)$ & Control subjects (group III) $(\boldsymbol{n}=40)$ & $\boldsymbol{P}$ value & Pairs \\
\hline \multicolumn{6}{|l|}{ Genotype } \\
\hline TT & $5(11.9 \%)$ & $2(4.3 \%)$ & $2(5 \%)$ & 0.003 & $1 * 2=0.043$ \\
\hline GT & $21(50 \%)$ & $15(31.9 \%)$ & $6(15 \%)$ & & $1 * 3=0.001$ \\
\hline GG & $16(38.1 \%)$ & $30(63.8 \%)$ & $32(80 \%)$ & & $2 * 3=0.184$ \\
\hline Genotype & & & & & $1 * 2=0.015$ \\
\hline $\mathrm{TT}$ or GT & $26(61.9 \%)$ & $17(36.2 \%)$ & $8(20 \%)$ & $<0.001$ & $1 * 3<0.001$ \\
\hline GG & 16 (38.1\%) & $30(63.8 \%)$ & $32(80 \%)$ & & $2 * 3=0.097$ \\
\hline
\end{tabular}


Table 3 The genotypes of MUC5B promoter polymorphism as regards gender among the 3 studied groups

\begin{tabular}{llll}
\hline Genotype & Female gender & Male gender & $P$ value \\
\hline IPF patients (group I) & & & \\
GT and TT & $13(50 \%)$ & $13(50 \%)$ & 0.109 \\
GG & $4(25 \%)$ & $12(75 \%)$ & \\
Other ILD patients (group II) & & & \\
GT and TT & $14(82.4 \%)$ & $3(17.6 \%)$ & 0.647 \\
GG & $23(76.7 \%)$ & $7(23.3 \%)$ & \\
Control subjects (group III) & & & \\
GT and TT & $6(75 \%)$ & $2(25 \%)$ & 1.000 \\
GG & $24(75 \%)$ & $8(25 \%)$ & \\
\hline
\end{tabular}

genotype (TT) among the 40 normal individuals, indicating that the $\mathrm{T}$-allele polymorphism percentage was approximately $20 \%$ in our sample. Other studies conducted on other Caucasian populations demonstrated that the T-allele percentage was $10.81 \%, 11.74 \%, 10 \%$, and $9.1 \%$ in the French, Italian, UK, and in the US Caucasian population, respectively [17-19].

Our results revealed that the minor-allele (T) polymorphism in the IPF patients (group I) was present in 21 patients as heterozygous G/T genotype and in 5 patients as homozygous $\mathrm{T} / \mathrm{T}$ genotype, denoting that the $\mathrm{T}$-allele frequency was approximately $61.9 \%$ among the IPF patients. Also, the presence of the allele (T) polymorphism in the other ILD patients (group II) was detected in 15 patients as the heterozygous G/T genotype and in 2 patients as homozygous $\mathrm{T} / \mathrm{T}$ genotype, showing that the $\mathrm{T}$-allele polymorphism was approximately $36.1 \%$ among the other ILD patients. The (T) allele frequency was significantly higher among the IPF patients (group I) in relation to the other two groups $(P$ value $<0.001)$. Hence, our data support a strong correlation between the $\mathrm{T}$-allele of the mucin gene subtype $\mathrm{B}$ and the occurrence of IPF, in the Egyptian patients which is the same

Table 4 The genotypes of MUC5B promoter polymorphism as regards the smoking status among the 3 studied groups

\begin{tabular}{llll}
\hline Genotype & Smokers & Non smokers & P value \\
\hline IPF patients (group I) & & & \\
GT and TT & $13(50 \%)$ & $13(50 \%)$ & 0.014 \\
GG & $2(12.5 \%)$ & $14(87.5)$ & \\
Other ILD patients (group II) & & & \\
GT and TT & $2(11.8 \%)$ & $15(88.2 \%)$ & 0.850 \\
GG & $3(10 \%)$ & $27(90 \%)$ & \\
Control subjects (group III) & & & \\
GT and TT & $2(25 \%)$ & $6(75 \%)$ & 0.650 \\
GG & $6(18.8 \%)$ & $26(81.3 \%)$ & \\
\hline
\end{tabular}

to the studies in the Caucasian population in Europe and the USA $[15,17,22]$.

A Chinese study concluded that the frequency of the (T) allele in normal Chinese persons was approximately $0.66 \%$, which was lower than that described in the Caucasian population and our study. However, the frequencies of the $\mathrm{T}$ allele were significantly higher among their IPF and ILD patients than healthy Chinese controls, $3.33 \%$ and $2.22 \%$ respectively [23].

In this study, the T-allele of the MUC5B in other ILD patients was not significantly different compared to the control subjects. A finding that suggests the absence of any relation between MUC5B polymorphism and lung fibrosis in the context of autoimmune conditions, either NSIP or UIP.

It is clear that IPF is higher in older age groups. In our study, the mean age of IPF patients was (47.8 \pm 8.8 years). Our findings were similarly in line to a study conducted by Kaddah et al., which included 102 IPF patients from Egypt; the mean age of their patients was $50 \pm 13$ years [24]. Also, our results goes with that of an Egyptian study that was conducted in Upper Egypt and showed that the mean age of their IPF patients was $44 \pm$ 12 years [25].

In multiple studies, IPF appears to have sex predilection being more common in men; some suppose that this difference may be related to smoking patterns rather than sex as a risk for IPF [26, 27]. This is against our results in which most of the IPF patients (group I) were females (59.5\%). All of them were non-smokers and housewives. Only $33.3 \%$ and $36.2 \%$ of the female IPF and other ILD patients gave history of raising birds respectively. There were 17 male IPF patients (40.5\%); 35.7\% gave history of cigarette smoking compared to 10 male IPF patients (21.3\%); $10.6 \%$ gave history of cigarette smoking. Interestingly, our results matched that of a study conducted by Sherbini et al., which included 134 IPF patients from Saudi Arabia; 56\% of their patients were females and $44 \%$ were males; smoking was more evident as $36 \%$ of IPF patients were smokers [28].

In this study, the frequency of the $\mathrm{T}$ allele of MUC5B among male individuals (25\%) was lower than female individuals $(75 \%)$ in the control group, but it was statistically insignificant $(P=1.000)$. Moreover, we investigated the possibility of the affection of a function of MUC5B gene by gender among our IPF patients. The results did not detect any significance in the $\mathrm{T}$ allele percentage between both female (82.4\%) and male ILD (17.6\%) patients and their normal pair controls as well as between female $(50 \%)$ and male (50\%) IPF patients and matched controls. Borie et al. reported that the $\mathrm{T}$ allele risk was not affected by sex in Caucasians [17]. They considered that the mucin 5B subtype could have an independent effect on the liability to IPF. However, in the Chinese study, 
Table 5 The genotypes of MUC5B promoter polymorphism as regards the history of raising birds among the IPF patients and the other ILD patients groups

\begin{tabular}{lll}
\hline Genotype & Raising birds subjects & Non raising birds subjects \\
\hline IPF patients (group I) & & \\
GT and TT & $4(15.4 \%)$ & $22(84.6 \%)$ \\
GG & $10(62.5 \%)$ & $6(37.5 \%)$ \\
Other ILD patients (group II) & & \\
GT and TT & $6(35.3 \%)$ & $11(64.7 \%)$ \\
GG & $11(36.7 \%)$ & $19(63.3 \%)$ \\
\hline
\end{tabular}

the $(\mathrm{T})$ allele percent was considerably lower in the Chinese population and significantly differed between Chinese males and females. The $\mathrm{T}$ allele was significantly higher among male IPF patients compared with the corresponding healthy controls $(3.75 \%$ versus $0.37 \%, P=0.001)$, denoting the possible correlation between $\mathrm{T}$ allele of the mucin gene subtype B and IPF [23].

Detection of risk factors for IPF is a critical issue in order to take steps towards preventive strategies, early diagnosis, and novel therapies. Smoking is one of risk factors for IPF. Additionally, smoking appears as a cofactor for increasing MUC5B expression. Smoking could augment the level of MUC5B expressed by alveolar macrophages at the long term [29-34]. Recently, the smoking rates were high among both European males and females [35, 36]. Among our IPF patients, 15 males were smokers compared to only 5 males of other ILD group with positive statistical significance $(P$ value 0.006$)$. Also, the number of the IPF smoker patients was the highest compared to the other 2 groups ( $P$ value 0.016$)$. None of our female patients were smokers. This highlighted that the minor-allele $(\mathrm{T})$ in male IPF smoker patients was high with $P$ value $=0.014$. Our results suggest that smoking could accelerate the process of IPF in patients with the mucin gene $5 \mathrm{~B}$ variant. However, due to the lack of smoking among our Egyptian female patients, we failed to detect an association between the MUC5B polymorphism and female patients with IPF in this study.

One of the suggested risk factors for IPF is bird raising in Egypt. A multicenter hospital-based case control study from 2010 to 2011 performed in Egypt found strong occupational and exposure associations as woodworking and chemical/petrochemical industry for men and raising birds and farming for women and risk for IPF [37]. Our results showed that there were 14 subjects raising birds among the IPF patients (group I) compared to 17 subjects raising birds among the other ILD patients (group II) with no statistical significance between the 2 groups $(P$ value $=0.779)$. The percentage of the minor allele $(\mathrm{T})$ is $4(15.4 \%)$ among IPF raising birds patients (group I) while in the other ILD patient raising birds (group II), the configuration of the minor-allele (T) was present in $6(35.3 \%)$ cases. Our results showed that, despite there were 16 IPF female patients with GG phenotype for the MUC5B, the fact that 10 (62.5\%) of those patients were raising birds may had an influence and played an essential role for development of IPF in those patients. The environmental risk factors as raising birds may be a potential cause for development of IPF even with GG phenotype for the MUC5B subjects. However, multicentric researches are required to focus on the possibility of relation between the mucin $5 \mathrm{~B}$ gene and the bird-raising exposure in the pathogenesis of IPF.

In this study, the mucin gene subtype B polymorphism was not associated with disease severity as evidenced by FVC values and oxygen saturation values of our patients in both groups. However, in the Chinese study performed by Jiang et al., the MUC5B is associated with IPF severity [38].

This study has limitations as the relatively small numbers in each group and high cost of laboratory kits. Future researches in Egypt using larger patient cohorts are required to confirm the findings of this study.

\section{Conclusions}

The (T) allele of the MUC5B in the sample of Egyptian population is relatively higher than that in other Caucasians. This variant significantly associated with the possibility of developing IPF in Egyptian patients, although it might not be the essential factor for IPF in Egypt. The MUC5B variant is not a risk for lung fibrosis associated in autoimmune conditions.

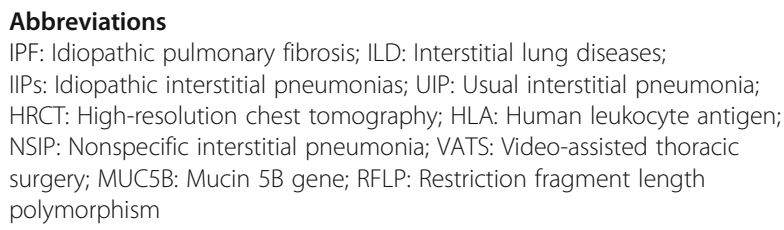

\section{Acknowledgements}

Not applicable

\section{Authors' contributions}

HAY, SK, MG, and HM had put the design and frame of the work; MS had collected, analyzed, and interpreted data regarding patients with ILD who had done HRCT chest. HM had drafted the work, revised it, and was a major contributor in writing manuscript. MM was a major contributor in 
interpreting pathological data. HAY, SK, and MG had read and approved final manuscript.

\section{Funding}

None

\section{Availability of data and materials}

Not applicable.

\section{Ethics approval and consent to participate}

The referred subjects were asked for informed written consent after fulfilling the inclusive and exclusive criteria of the study. The study was approved by the ethical committee of Faculty of Medicine, Cairo University. IRB was not necessary according to national regulations at time of starting the study. Committee's reference number is not available.

\section{Consent for publication}

Consent for publication was taken from all authors.

\section{Competing interests}

None

\section{Author details}

${ }^{1}$ Chest Department, Cairo University, Giza, Egypt. ${ }^{2}$ Clinical Pathology, Cairo University, Giza, Egypt.

Received: 17 April 2020 Accepted: 15 July 2020

Published online: 31 July 2020

\section{References}

1. Raghu G, Collard HR, Egan JJ et al (2011) ATS/ERS/JRS/ ALAT Committee on Idiopathic Pulmonary Fibrosis. An official ATS/ERS/JRS/ALAT statement: idiopathic pulmonary fibrosis: evidence-based guidelines for diagnosis and management. Am J Respir Crit Care Med 183:788-824

2. Raghu G, Weycker D, Edelsberg J et al (2006) Incidence and prevalence of idiopathic pulmonary fibrosis. Am J Respir Crit Care Med. 174:810-816

3. American Thoracic Society/European Respiratory Society (2013) An Official American Thoracic Society/European Respiratory Society Statement: update of the International Multidisciplinary Classification of the Idiopathic Interstitial. Am J Respir Crit Care Med 188:733-748

4. Lai CC, Wang CY, Lu HM et al (2012) Idiopathic pulmonary fibrosis in Taiwan - a population-based study. Respir Med 106:1566-1574

5. Olson A, Swigris J, Lezotte D et al (2007) Mortality from pulmonary fibrosis increased in the United States from 1992 to 2003. Am. J. Respir. Crit. Care Med 176(3):277-284

6. Coultas D, Zumwalt R, Black W et al (1994) The epidemiology of interstitial lung diseases. Am J Respir Crit Care Med 150:967-972

7. Meltzer E, Noble P (2008) Idiopathic pulmonary fibrosis. Orphanet J Rare Dis 3:8

8. Hubbard R, Lewis S, Richards K et al (1996) Occupational to exposure to metal or wood dust and aetiology of cryptogenic fibrosing alveolitis. Lancet 347:284-289

9. Baumgartner KB, Samet JM, Stidley CA et al (1997) Cigarette smoking: a risk factor for idiopathic pulmonary fibrosis. Am J Respir Crit Care Med 155:242248

10. Zhang X, Jiang J, Chen WJ et al (2012) Genetic characterization of a Chinese family with familial idiopathic pulmonary fibrosis. Chin Med J (Engl) 125: 1945-1951

11. King TE, Pardo A, Selman M (2011) Idiopathic pulmonary fibrosis. Lancet 378 : 1949-1961

12. Cui Y, Osorio JC, Risquez C et al (2014) Transforming growth factor-beta1 downregulates vascular endothelial growth factor-D expression in human lung fibroblasts via the Jun $\mathrm{NH}$-terminal kinase signaling pathway. Mol Med 20:120-134. 12

13. Zhang J, Xu DJ, XU KF et al (2012) HLA-A and HLA-B gene polymorphism and idiopathic pulmonary fibrosis in a Han Chinese population. Respir Med 106:1456-1462

14. Hutyrova B, Pantelidis P, Drabek J et al (2002) Interleukin-1 gene cluster polymorphisms in sarcoidosis and idiopathic pulmonary fibrosis. Am J Respir Crit Care Med 165:148-151
15. Stock CJ, Sato H, Fonseca C et al (2013) Mucin 5B promoter polymorphism is associated with idiopathic pulmonary fibrosis but not with development of lung fibrosis in systemic sclerosis or sarcoidosis. Thorax 68:436-441

16. Peljto AL, Steele MP, Fingerlin TE et al (2012) The pulmonary fibrosis-associated MUC5B promoter polymorphism does not influence the development of interstitial pneumonia in systemic sclerosis. Chest 142:1584-1588

17. Borie R, Crestani B, Dieude P et al (2013) The MUC5B variant is associated with idiopathic pulmonary fibrosis but not with systemic sclerosis interstitial lung disease in the European Caucasian population. PLoS One 8:e70621

18. Fingerlin TE, Murphy E, Zhang W et al (2013) Genome-wide association study identifies multiple susceptibility loci for pulmonary fibrosis. Nat Genet 45:613-620

19. Noth I, Zhang Y, Ma SF et al (2013) Genetic variants associated with idiopathic pulmonary fibrosis susceptibility and mortality: a genome-wide association study. Lancet Respir Med 1:309-317

20. Thornton DJ, Devine PL, Hanski C et al (1994) Identification of two major populations of mucins in respiratory secretions. Am J Respir Crit Care Med 150:823-832

21. Kirkham S, Kolsum U, Rousseau K et al (2008) MUC5B is the major mucin in the gel phase of sputum in chronic obstructive pulmonary disease. Am J Respir Crit Care Med 178:1033-1039

22. Seibold MA, Wise AL, Speer MC et al (2011) A common MUC5B promoter polymorphism and pulmonary fibrosis. N Engl J Med 364:1503-1512

23. Wang C, Zhuang Y, Guo W et al (2014) Mucin 5B promoter polymorphism is associated with susceptibility to interstitial lung diseases in Chinese males. PLoS One 9:e104919

24. Kaddah S, Ahmed S (2016) Life style associated diseases in patients with intestinal pulmonary fibrosis. The Egyptian society of chest diseases and tuberculosis 65:127-133

25. Rashad MA, Ibrahim AK (2015) Idiopathic pulmonary fibrosis (IPF) in Upper Egypt, a single center study. The Egyptian society of chest diseases and tuberculosis 64:915-919

26. Olson A, Swigris J, Lezotte D et al (2007) Mortality from pulmonary fibrosis increased in United States from 1992-2003. Am J Respir Crit Care Med 176: 277-284

27. Mannino DM, Etzel RA, Parrish RG (1996) Pulmonary fibrosis deaths in the United States, 1979-1991. An analysis of multiple-cause mortality data. Am J Respir Crit Care Med 153:1548-1552

28. Sherbini N, Feteih M, Wali S et al (2014) Idiopathic pulmonary fibrosis in Saudi Arabia: demographic, clinical and survival data from two tertiary hospitals. Ann Thorac Med 9:168-117

29. Plantier L, Crestani B, Wert SE et al (2011) Ectopic respiratory epithelial cel differentiation in bronchiolised distal airspaces in idiopathic pulmonary fibrosis. Thorax 66:651-657. 41

30. O'Donnell RA, Richter A, Ward J et al (2004) Expression of ErbB receptors and mucins in the airways of long term current smokers. Thorax 59:10321040. 42

31. Leikauf GD, Borchers MT, Prows DR et al (2002) Mucin apoprotein expression in COPD. Chest 121:166S-182S. 43

32. Choi Wl, Syrkina O, Kwon KY et al (2010) JNK activation is responsible for mucus overproduction in smoke inhalation injury. Respir Res 11:172-144

33. Ekstrom M, Gustafson $T$, Boman $\mathrm{K}$, et al. Effects of smoking, gender and occupational exposure on the risk of severe pulmonary fibrosis: a population-based case-control study. BMJ 2014, Open 4: e004018.

34. Sepper R, Prikk K, Metsis M et al (2012) Mucin5B expression by lung alveolar macrophages is increased in long-term smokers. J Leukoc Biol 92:319-324

35. Gorini G, Carreras G, Allara E et al (2013) Decennial trends of social differences in smoking habits in Italy: a 30-year update. Cancer Causes Control 24:1385-1391

36. World Health Organization (WHO) (2012) Tobacco control in practice. WHO regional office for Europe, Copenhagen

37. Awadalla NJ, Hegazy A, Elmetwally RA et al (2012) Occupational and environmental risk factors for idiopathic pulmonary fibrosis in Egypt: a multicenter case-control study. Int J Occup Environ Med 3:107-116

38. Jiang H, Hu Y, Shang L et al (2015) Association between MUC5B polymorphism and susceptibility and severity of idiopathic pulmonary fibrosis. Int J Clin Exp Pathol 8(11):14953-14958

\section{Publisher's Note}

Springer Nature remains neutral with regard to jurisdictional claims in published maps and institutional affiliations. 